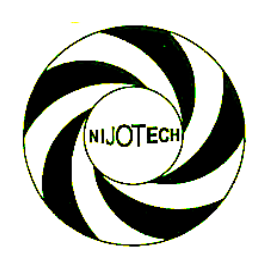

Nigerian Journal of Technology (NIJOTECH)

Vol. 38, No. 2, April 2019, pp. 348 - 354

Copyright@ Faculty of Engineering, University of Nigeria, Nsukka

Print ISSN: 0331-8443, Electronic ISSN: 2467-8821 www.nijotech.com

http://dx.doi.org/10.4314/njt.v38i2.11

\title{
A NUMERICAL INVESTIGATION OF MANGO LEAVES-WATER NANOFLUID UNDER LAMINAR FLOW REGIME
}

\author{
E. J. Onyiriuka ${ }^{1}$ and E. A. Ikponmwoba ${ }^{2, *}$

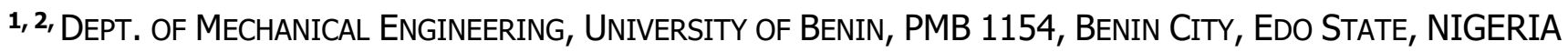 \\ E-mail addresses: ${ }^{1}$ ekene.onyiriuka@uniben.edu, 2 eloghosaefficiency@gmail.com
}

\begin{abstract}
Nanofluids are solid-liquid composites which show higher convective heat transfer performance than conventional heat transfer fluids. However, most of the nanoparticles used are metallic oxides which are known to be toxic both to the environment and humans. Hence, the study of bionanomaterial to which the environment is naturally exposed is an important study. These biomaterials are the additives to the base fluid. Mango leaves-water nanofluid is the nanofluid being studied under laminar flow conditions in a horizontal pipe. The multi-phase mixture model was used to simulate the nanofluid behavior. ANSYS Fluent 18.2 finite volume commercial code was used to discretize and solve the governing equations of flow and energy with residuals set to $10^{-6}$ for each governing equation. The Semi-Implicit method for pressure linked equations algorithm [SIMPLE] was used for pressure-velocity coupling. It was observed that the local heat transfer coefficient always decreased with the axis location. $A 12 \%$ increase of the average heat transfer coefficient was observed for $3 \%$ volume fraction of mango leaves-water nanofluid in comparison to the base fluid. Hence there are great prospects for the use of these fluids as heat transfer fluids it being superior to the base fluid in terms of heat transfer characteristics.
\end{abstract}

Keywords: Bio-materials, Nanofluid, Numerical modeling, Heat transfer enhancement, mixture model

\section{INTRODUCTION}

Nanofluids are solid-liquid mixtures where the solids are of nanometre sizes and are suspended stably in a base fluid such as water. They have been found to have superior heat transfer properties than conventional fluids like water, glycol-based coolants, engine oil, transformer oil etc. The nanoparticles could be metallic, non-metallic, ceramics etc. Due to a high growth of the use of technology, there has been an increased need for fluids with higher heat transfer properties and a need for highly optimized and smart systems of which many researchers look to nanofluids as a solution to these requirements.

There have been both numerical and experimental studies on the heat transfer characteristics of nanofluid flow in tubes [1-7]. Some analytical and experimental results $[8,9]$ show that an effective method to reduce the thermal resistance and entropy generation in a heat pipe could be achieved by using a nanofluid as the working fluid. It was found by experimental work of Wen and Ding [10] that nanofluids possess higher heat transfer characteristics than the base fluid and that this enhancement was greater in the developing region than in the developed region. Numerical investigation for water- $\mathrm{Al}_{2} \mathrm{O}_{3}$ nanofluid inside a circular tube under constant wall heat flux was carried out by several researchers $[2,5]$. Mirmasoumi and Behzadmehr [11] found that using the mixture model under laminar flow regime showed good agreements with experiments and that the nanoparticle concentration has a significant effect on thermal parameters and no important effect on hydrodynamic parameters. They stated significant enhancement on the Nusselt number by increasing the nanoparticles volume fractions. Yurong et al. [12] numerically studied the forced convective heat transfer of $\mathrm{TiO}_{2}$ nanofluids under laminar flow conditions. Their results show significant enhancement of heat transfer of nanofluids, particularly in the entrance region. 
Nanofluids are applied in many heat transfer scenarios like cooling systems in buildings, automobiles, and avionics, cooling high power electronics, cooling reactors with an exothermic reaction, industrial process heating $[13,14]$. However, there are issues as reported by researchers [15-19] due to their use of metallic oxides on their effect on the health safety and environment due to the use of these fluids. Weisheng Lin et al. [15] published that exposure to $70 \mathrm{~nm}$ and $420 \mathrm{~nm}$ of $\mathrm{ZnO}$ particles leads to dose- and timedependent cytotoxicity (toxic to cells) reflected in oxidative stress, lipid peroxidation, cell membrane damage, and oxidative DNA damage. Song et al. [16] also stated that the brain which consumes a large amount of oxygen is the primary target of metallic nanoparticles once they enter into the body. Furthermore, Simonin and Richaume [17] stated that nanoparticles specifically those made of silver, copper, and zinc have anti-microbial properties which could pose a threat to beneficial microbial communities (bacteria, fungi, and archaea) which are found in soils. Zhang et al. [19] stated that there is increased pollution on the environment due to shape, size and chemical compositions of some of the nanotechnology products. They suggested that choosing less toxic materials will make huge impacts on the environment. Although there have been many studies on nanofluids there are only a few in the open literature that look into the use of bio-materials for nanoparticles. Solomon et al. [20] studied the convective heat transfer with water-based mango bark nanofluids and found that the natural convective process is deteriorated with the addition of mango nanoparticles in de-ionized water. As has been already enumerated, conventional nanofluids have health and environmental issues with their use. Hence, this study focuses on studying a new class of nanofluids which are healthy and environmentally friendly.

In our study, we investigate forced convective flow of mango leaves-water nanofluid inside a circular tube under constant wall heat flux boundary condition. ANSYS Fluent software is used to solve the governing equation by means of a finite volume method. The mixture model was used to model the nanofluid.

\section{MATHEMATICAL MODELLING}

Fig. 1 shows the considered geometrical configuration. A two dimensional (2D) axisymmetric was considered; a very fine mesh near the tube wall was used in order to capture the near wall behavior of the nanofluid. A non-uniform quadratic mesh is used as shown in Fig. 1. It consists of a tube with length ( $L$ ) of $1.0 \mathrm{~m}$ and circular cross-section with the diameter $(D)$ equal to $0.019 \mathrm{~m}$. The considered nanofluid is a mixture composed of water and particles of mango leaves of $100 \mathrm{~nm}$ particle size.

\subsection{Governing equations}

As reported by Kristiawan, et al [21] in his study of laminar convective heat transfer of $\mathrm{TiO}^{-}$-water nanofluid, the two-phase mixture model accurately predicted the heat transfer coefficient. Hence the model employed to analyze the thermal and fluid dynamic behavior of the considered nanofluid in this study was the mixture model, where the two-phases are considered. The nanofluid is considered to be a single fluid with two phases and the coupling between them is strong, each phase has its own velocity vector field and there is a certain fraction of each phase in a particular control volume under consideration.
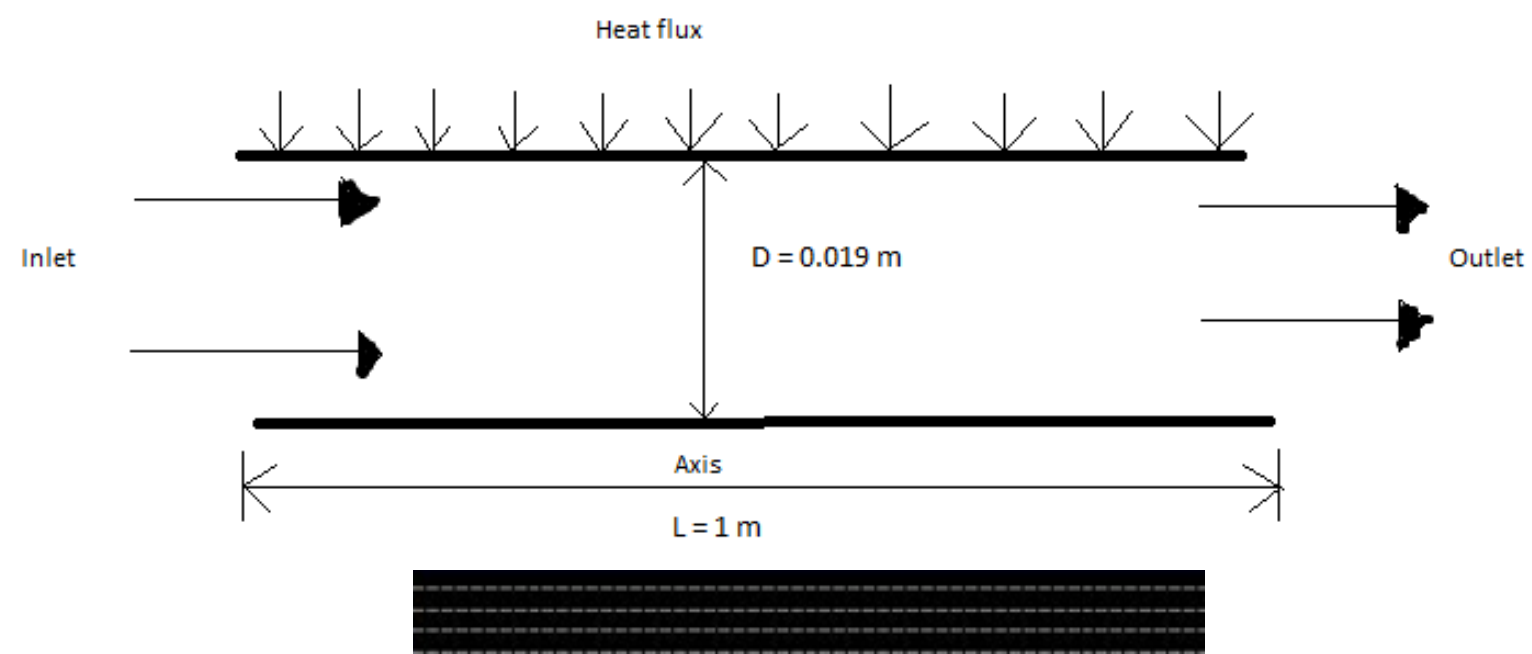

Figure. 1. Geometrical and mesh configurations for the current study 
The mixture model solves an additional equation which is the volume fraction equation for the secondary phase in addition to the continuity, momentum and energy equations and then calculates the relative velocity between the phases using an algebraic expression.

The governing equations of the mixture model are presented below:

$$
\nabla \cdot\left(\rho_{m} \vec{v}_{m}\right)=0
$$

Equation (1) was adopted to present continuity equation:

$$
\begin{aligned}
\nabla \cdot\left(\rho_{m} \vec{v}_{m} \vec{v}_{m}\right)= & -\nabla p+\nabla \cdot\left(\mu_{m} \nabla \vec{v}_{m}\right) \\
& +\nabla \cdot\left(\sum_{k=1}^{n} \phi_{k} \rho_{k} \vec{v}_{d r, k} \vec{v}_{d r, k}\right)
\end{aligned}
$$

Momentum was established by equation (2)

$$
\nabla .\left[\sum_{k=1}^{n} \phi_{k} \vec{v}_{k}\left(\rho_{k} H_{k}+p\right)\right]=\nabla \cdot(k \nabla T)
$$

Energy was established by equation (3)

$$
\nabla \cdot\left(\phi_{p} \rho_{p} \vec{v}_{m}\right)=-\nabla \cdot\left(\phi_{p} \rho_{p} \vec{v}_{d r, p}\right)
$$

Equation (4-8) represents volume fractions

$$
\begin{aligned}
\vec{v} & =\sum_{k=1}^{n} \frac{\phi_{k} \rho_{k} \vec{v}_{k}}{\rho} \\
\rho & =\sum_{k=1}^{n} \phi_{k} \rho_{k} \\
\mu & =\sum_{k=1}^{n} \phi_{k} \mu_{k} \\
k & =\sum_{k=1}^{n} \phi_{k} k_{k}
\end{aligned}
$$

where $\mathrm{v}, \rho, \mu, X, \vec{v}, \mathrm{~g}, v_{d r}, p, H_{k}, \lambda, \mathrm{T}$ and $\mathrm{nf}$ are velocity $(\mathrm{m} / \mathrm{s})$, density $(\mathrm{kg} / \mathrm{m} 3)$, viscosity $(\mathrm{kg} / \mathrm{ms})$, concentration, time average velocity component $(\mathrm{m} / \mathrm{s})$, Acceleration due to gravity $\left(\mathrm{m}^{2} / \mathrm{s}\right)$, Drift velocity $(\mathrm{m} / \mathrm{s})$, Pressure $\left(\mathrm{N} / \mathrm{m}^{2}\right)$, Sensible enthalpy for phases, Thermal conductivity $(\mathrm{W} / \mathrm{m}-\mathrm{K})$, temperature and nanofluid respectively.

The drift velocity $\left(\vec{v}_{d r, k}\right)$ for the secondary phase is presented with the aid of equation (9)

$$
\vec{v}_{d r, k}=\vec{v}_{k}-\vec{v}_{m}
$$

Equation (10) is adopted to present the relative or slip velocity which is the velocity of the secondary phase $(p)$ relative to the velocity of the primary phase (f):

$$
\vec{v}_{p f}=\vec{v}_{p}-\vec{v}_{f}
$$

The drift velocity related to the relative velocity was presented with the aid of equation (11)

$$
\vec{v}_{d r, p}=\vec{v}_{p f}-\sum_{k=1}^{n} \frac{\vec{v}_{f k} \phi_{k} \rho_{k}}{\rho_{m}}
$$

Manninen, et $a /$ [22] and Naumann and Schiller [23] proposed the equations (12) and (13) for relative velocity $\vec{v}_{p f}$ and the drag function $f_{\text {drag }}$.

$$
\begin{aligned}
\vec{v}_{p f} & =\frac{\rho_{p} d_{p}{ }^{2}}{18 \mu_{m} f_{\text {drag }}} \frac{\rho_{p}-\rho_{m}}{\rho_{p}} \vec{a} \\
f_{\text {drag }} & =\left\{\begin{array}{c}
1+0.15 \operatorname{Re}_{p}{ }^{0.687} \operatorname{Re}_{p} \leq 1000 \\
0.0183 R e_{p} \operatorname{Re}_{p} \geq 1000
\end{array}\right.
\end{aligned}
$$

The acceleration is determined with equation (14).

$$
\vec{a}=\vec{g}-\left(\vec{v}_{m} . \nabla\right) \vec{v}_{m}
$$

$d_{p}$ and $\vec{a}$ represents the diameter of the nanoparticles of the secondary phases and the secondary phase particles acceleration.

\subsection{Boundary conditions}

At the inlet of the tube, profiles of uniform axial velocity $V_{0}$ and temperature, $T_{0}=293 \mathrm{~K}$ are set. Noslip conditions and uniform heat flux are imposed at the tube's wall. A two-dimensional (2D) axisymmetric assumption is employed.

\subsection{Nanofluids thermophysical properties 2.4.1 Density}

The density of the nanofluid is given by equation(15) as reported in [24];

$$
\rho_{n f}=(1-\phi) \rho_{f}+\phi \rho_{p}
$$

where $\phi$ is the nanoparticle concentration, $\rho_{f}$ and $\rho_{p}$ are the density of the base fluid and nanoparticle, respectively.

\subsubsection{Specific Heat}

The specific heat capacity of the nanofluid is described by equation (16) as mentioned elsewhere [25]

$$
(\rho C p)_{n f}=(1-\phi)(\rho C p)_{f}+\phi(\rho C p)_{p}
$$

where $(\rho C p)_{f}$ and $(\rho C p)_{p}$ are the heat capacitance of base fluid and nanoparticle respectively.

\subsubsection{Viscosity}

The viscosity is presented in equation (17) as in [7, $25,26]$ :

$$
\frac{\mu_{n f}}{\mu_{b f}}=123 \phi^{2}+7.3 \phi+1
$$

\subsubsection{Thermal conductivity}

The thermal conductivity is presented in equation (18) as presented elsewhere in $[7,25,26]$ :

$$
\frac{k_{n f}}{k_{b f}}=4.97 \phi^{2}+2.72 \phi+1
$$


The thermophyical properties of mango leaves and base fluid are represented by equations (19) and (20), respectively

$$
\begin{gathered}
\rho_{p}=747 \mathrm{~kg} / \mathrm{m3} ; C p_{p}=1545 \mathrm{~kJ} /(\mathrm{kg} \mathrm{K}) ; \\
k_{p}=0.41 \mathrm{~W} /(\mathrm{m} \mathrm{K}) \\
\rho=998.2 \mathrm{~kg} / \mathrm{m}^{3} ; C p=4182 \mathrm{~kJ} /(\mathrm{kg} \mathrm{K}) ; \\
k=0.597 \mathrm{~W} /(\mathrm{m} \mathrm{K}) ; \mu=0.000993 \mathrm{~kg} /(\mathrm{m} \mathrm{s})
\end{gathered}
$$

\section{NUMERICAL METHOD, VALIDATION AND GRID INDEPENDENCE}

The Fluent commercial code was used to solve the problem. The governing equations were solved by finite volume method which is based on the spatial integration of the conservation equations over finite control volumes which converts the governing equations to a set of algebraic equations and are then solved throughout the fluid domain. The residuals from the integration of the governing equation were set as convergence indicators with a value of $10^{-6}$. The SIMPLE algorithm was used to carry out pressure-velocity coupling. PRESTO scheme for pressure, QUICK for volume fraction and SECOND ORDER UPWIND for other parameters were considered to discretize the governing equations. The computer model was successfully validated with correlation reported in [27] for thermally and hydraulically developing flow, with an average error less than $10 \%$ as reported in Fig. 2 the local Nusselt number is determined with equation (21)

$$
N u(z)=\frac{h(z) \cdot D}{k_{0}}
$$

where $z$ is the axial distance, $h$ is the local heat transfer coefficient, $k_{0}$ is the thermal conductivity at the inlet, $D$ is the pipe diameter and $N u$ is the nusselt number; $h(z) \mathrm{d}$ is defined by equation (22)

$$
h(z)=\frac{q}{T(z)_{w}-T(z)_{b}}
$$

where $q$, is the heat flux applied and $T_{w}$ and $T_{b}$ are bulk mean temperatures from the previous equation the $h_{a v}$ (the average heat transfer coefficient) is defined by equation (23)

$$
h_{a v}=\frac{1}{L} \int_{0}^{L} h(z) d z
$$

And the average Nusselt number is defined by equation (24)

$$
N u_{a v}=\frac{h_{a v} \cdot D}{k_{0}}
$$

\section{RESULTS}

Results were obtained for two phase models for $\phi=$ $1 \%, 2 \%, 3 \%$ and $\operatorname{Re}=250,500,1000,1250$ and $q$ $=5000 \mathrm{~W} / \mathrm{m}^{2}$, the size of the spherical particles is $100 \mathrm{~nm}$. Fig. 3 shows the profiles of axial velocity along the tube radius of up to $\mathrm{z} / \mathrm{L}=0.10$ for $\mathrm{Re}=250$ and $q=5000 \mathrm{~W} / \mathrm{m}^{2}$ and $\phi=1 \%$. It can be observed that the nanofluid flow is fully developed at exit section located at $1.00 \mathrm{~m}$.

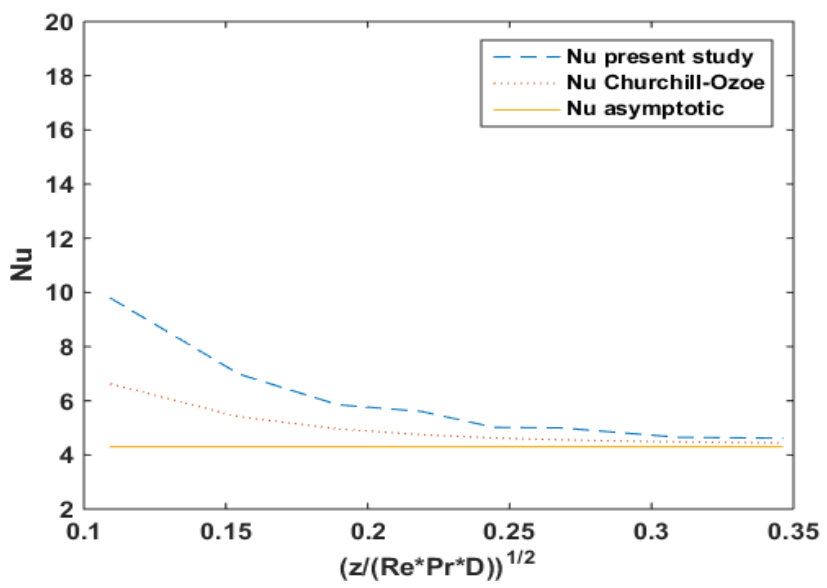

Figure. 2. Model validation with Churchill and Ozoe's correlation

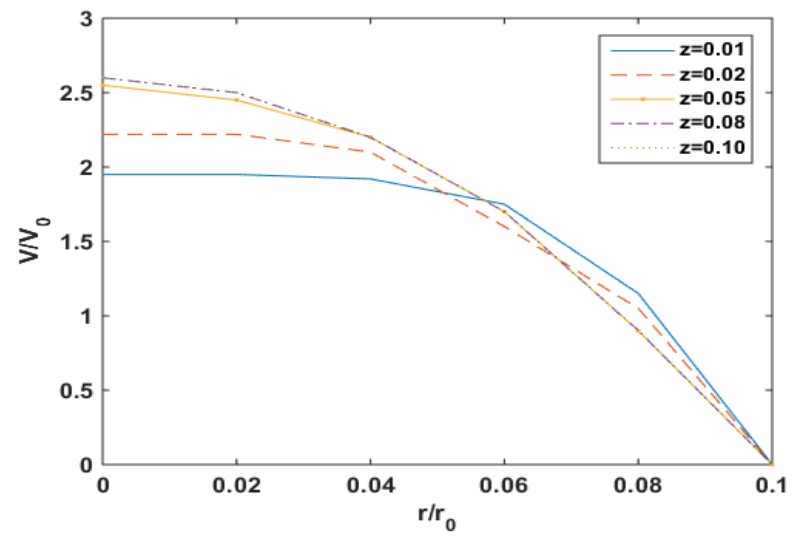

Figure 3. Comparison of the radial velocity profiles for $q=5000 \mathrm{~W} / \mathrm{m}^{2}, R e=250$ and $\phi=1 \%$

When concentration increases, the Prandtl number increases and the thermal entrance length which positively correlates with the Prandtl number also increases. The dimensionless temperature variation along the radius for several axial locations is shown in Fig. 4. It can be observed that the flow for water and nanofluid is not thermally developed.

The relative local heat transfer coefficient decreases with the axis location as shown in Fig. 5. With the highest values at the entrance region. The $\phi=3 \%$ line has the highest value showing that the heat transfer coefficient increases with concentration. 


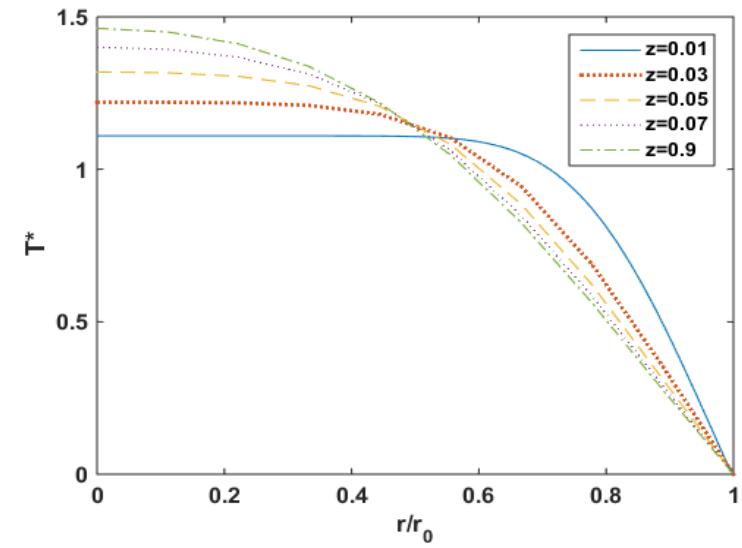

(a)

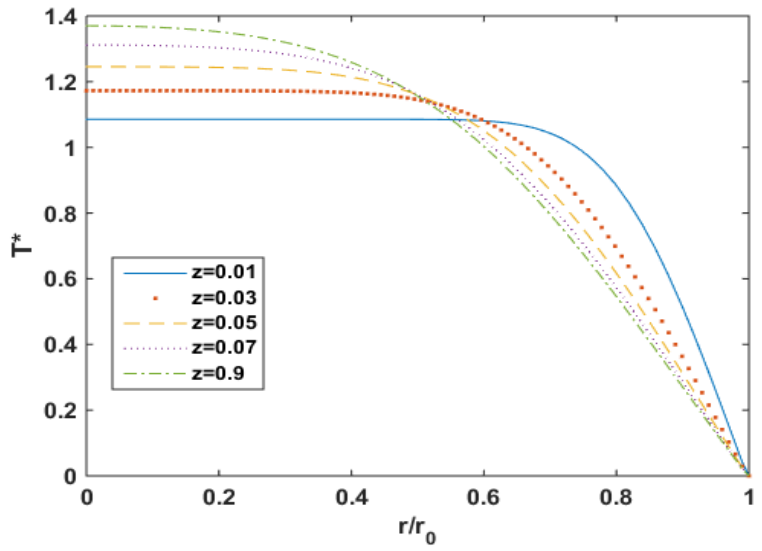

(b)

Figure 4: Comparison of the dimensionless temperature $\left(T^{*}\right)$ for $q=5000 \mathrm{~W} / \mathrm{m}^{2}$ and $R e=250$ at different axial locations for (a) $\phi=0 \%$ and (b) $\phi=1 \%$

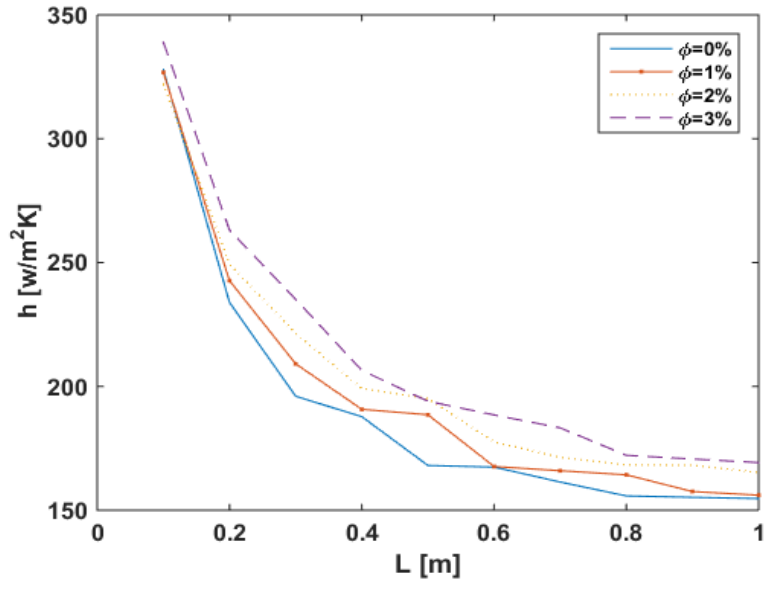

Figure 5. Heat transfer coefficient with the axis location for $q=5000 \mathrm{~W} / \mathrm{m} 2$.

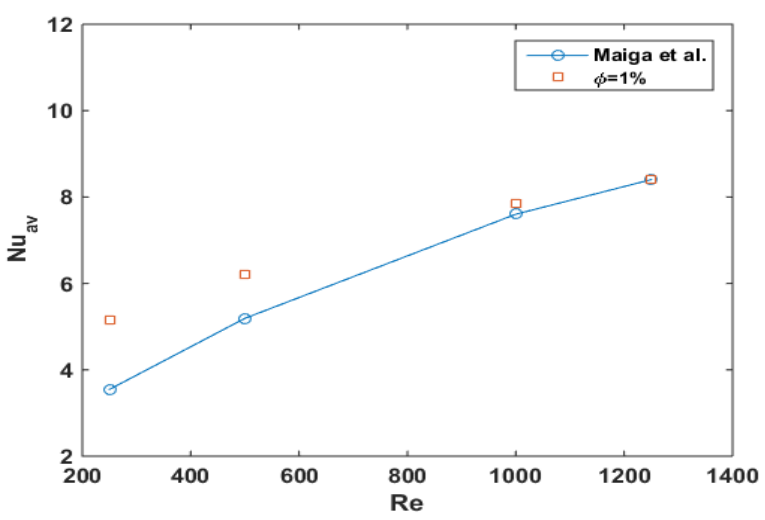

Figure 7(a). Comparison of Nusselt number as a function of Reynolds number with Maiga et al. [7] correlation.

Fig. 6 shows the average heat transfer coefficient variation with Reynolds number for each volume fraction of the nanofluid. It shows that the average heat transfer coefficient increases with Reynolds number, that is for a particular fluid and geometry the average heat transfer coefficient increases with

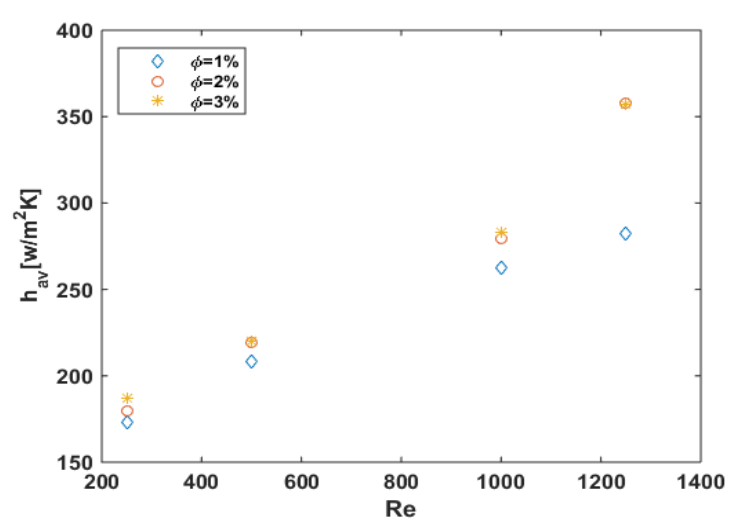

Figure. 6. Average heat transfer coefficient as a function of Reynolds number for

(a) $\phi=1 \%, \phi=2 \%, \phi=3 \%$

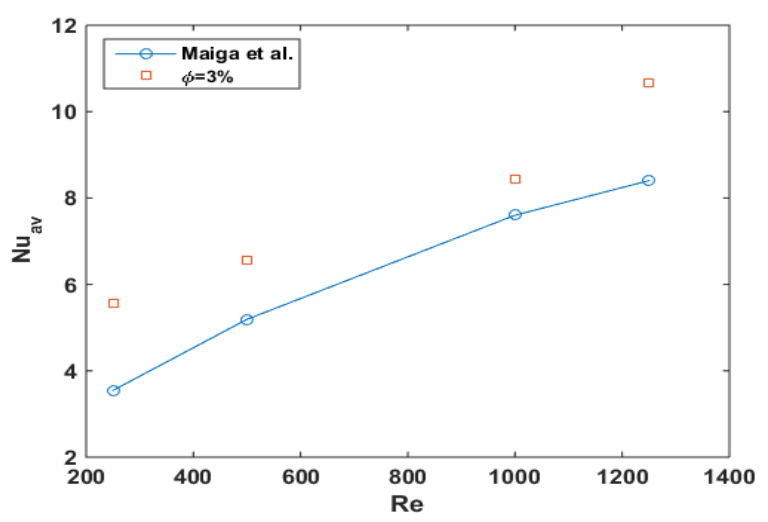

Figure $7(b)$. Comparison of Nusselt number as a function of Reynolds number with Maiga et al. [7] correlation.

flow velocity. However, the $\phi=2 \%$ and $3 \%$ volume fractions coincide as the flow velocity increases.

In Fig. 7a a comparison is made between correlations of Maiga et al. [7] and Nusselt number as a function of $\mathrm{Re}$ for the considered concentration. A good agreement is found between the correlations of 
Maiga et al. [7] at a volume fraction of $1 \%$ except for $\operatorname{Re}=250$.

The Fig. 7b shows misfit with Maiga et al. [7] for all Reynolds number.

Table 1. Values of $h n f / h b f$ for $R e=250$ and $q=$ $5000 \mathrm{~W} / \mathrm{m}^{2}$.

\begin{tabular}{lccc}
\hline & $\phi(\%)$ & $\mathrm{h}_{\mathrm{av}}$ & $\mathrm{h}_{\mathrm{nf}} / \mathrm{h}_{\mathrm{bf}}$ \\
\hline $\mathrm{H}_{2} \mathrm{O}$ & $0 \%$ & 166.6948 & 1 \\
$\begin{array}{l}\text { Mixture } \\
\text { model }\end{array}$ & $1 \%$ & 172.81 & 1.067 \\
$\begin{array}{l}\text { Mixture } \\
\text { model }\end{array}$ & $2 \%$ & 179.4280 & 1.0764 \\
$\begin{array}{l}\text { Mixture } \\
\text { model }\end{array}$ & $3 \%$ & 186.7451 & 1.1203 \\
\hline
\end{tabular}

From Table 1, it can be observed that there is a $6.7 \%$, $7.64 \%$, and $12.03 \%$ increase in heat transfer coefficient using mango leaves nanofluid of $1 \%, 2 \%$, $3 \%$ volume fractions respectively. From this table the improvement of heat transfer by using mango leaves nanofluid as against the base fluid (water) is apparent.

\section{CONCLUSION}

A numerical investigation into the heat transfer characteristics of mango leaves nanofluid under laminar flow regime in a circular tube was carried out. The mixture model with constant thermophysical properties was used to simulate the mango leaves nanofluid. The results showed that there was an increase in heat transfer coefficient when mango leaf is used as the nanoparticle and this increase is more as the volume fraction is increased. It was also observed that at higher Reynolds number and lower volume fraction there was good agreement with Maiga et al. [7] correlation. It was also found that the average Nusselt number increases with Reynolds number.

\section{REFERENCES}

[1] M. Shafahi, V. Bianco, K. Vafai, and O. Manca, "Thermal performance of flat-shaped heat pipes using nanofluids," International Journal of Heat and Mass Transfer, vol. 53, pp. 1438-1445, 2010.

[2] A. Albojamal and K. Vafai, "Analysis of single phase, discrete and mixture models, in predicting nanofluid transport," International Journal of Heat and Mass Transfer, vol. 114, pp. 225-237, 2017.

[3] D. Kim, Y. Kwon, Y. Cho, C. Li, S. Cheong, Y. Hwang, "Convective heat transfer characteristics of nanofluids under laminar and turbulent flow conditions," Current Applied Physics, vol. 9, pp. e119-e123, 2009.

[4] M. Mahdavi, "Study of flow and heat transfer features of nanofluids using multiphase models: eulerian multiphase and discrete Lagrangian approaches," University of Pretoria, 2017.

[5] V. Bianco, F. Chiacchio, O. Manca, and S. Nardini, "Numerical investigation of nanofluids forced convection in circular tubes," Applied Thermal Engineering, vol. 29, pp. 3632-3642, 2009.

[6] R. Lotfi, Y. Saboohi, and A. Rashidi, "Numerical study of forced convective heat transfer of nanofluids: comparison of different approaches," International Communications in Heat and Mass Transfer, vol. 37, pp. 74-78, 2010.

[7] S. E. B. Maiga, S. J. Palm, C. T. Nguyen, G. Roy, and N. Galanis, "Heat transfer enhancement by using nanofluids in forced convection flows," International journal of heat and fluid flow, vol. 26, pp. 530-546, 2005.

[8] M. Ghanbarpour, R. Khodabandeh, and K. Vafai, "An investigation of thermal performance improvement of a cylindrical heat pipe using $\mathrm{Al}_{2} \mathrm{O}_{3}$ nanofluid," Heat and Mass Transfer, vol. 53, pp. 973-983, 2017.

[9] K. Alizad, K. Vafai, and M. Shafahi, "Thermal performance and operational attributes of the startup characteristics of flat-shaped heat pipes using nanofluids," International Journal of heat and mass transfer, vol. 55, pp. 140-155, 2012.

[10] D. Wen and Y. Ding, "Experimental investigation into convective heat transfer of nanofluids at the entrance region under laminar flow conditions," International journal of heat and mass transfer, vol. 47, pp. 5181-5188, 2004.

[11] S. Mirmasoumi and A. Behzadmehr, "Numerical study of laminar mixed convection of a nanofluid in a horizontal tube using two-phase mixture model," Applied Thermal Engineering, vol. 28, pp. 717-727, 2008.

[12] Y. He, Y. Men, Y. Zhao, H. Lu, and Y. Ding, "Numerical investigation into the convective heat transfer of $\mathrm{TiO}_{2}$ nanofluids flowing through a straight tube under the laminar flow conditions," Applied Thermal Engineering, vol. 29, pp. 19651972, 2009.

[13] S. U. S. Choi, "Enhancing Thermal Conductivity of Fluids with Nanoparticles, Developments and Applications of NonNewtonian Flows,", pp. 99-105, 1995.

[14] S. Kakaç and A. Pramuanjaroenkij, "Review of convective heat transfer enhancement with 
nanofluids," International Journal of Heat and Mass Transfer, vol. 52, pp. 3187-3196, 2009.

[15] L. Weisheng, X. Yi, H. Chaun-Chin, Yinfa, Katie;, Da-Pen.;,"Toxicity of nano- and microsized $\mathrm{ZnO}$ particles on human lung epithelial cells," 2009.

[16] B. Song, Y. Zhang, J. Liu, X. Feng, T. Zhou, and L. Shao, "Is neurotoxicity of metallic nanoparticles the cascades of oxidative stress?," Nanoscale research letters, vol. 11, p. 291, 2016.

[17] M. Simonin and A. Richaume, "Impact of engineered nanoparticles on the activity, abundance, and diversity of soil microbial communities: a review," Enviromental Science and Pollution Research, 2015.

[18] L. Zhang, Y. Jiang, Y. Ding, M. Povey, and D. York, "Investigation into the antibacterial behaviour of suspensions of $\mathrm{ZnO}$ nanoparticles," Journal of Nanoparticle, vol. 9, pp. 479-489, 2007.

[19] L. Zhang, Y. Jiang, Y. Ding, M. Povey, and D. York, "Investigation into the antibacterial behaviour of suspensions of $\mathrm{ZnO}$ nanoparticles (ZnO nanofluids)," Journal of Nanoparticle Research, vol. 9, pp. 479-489, 2007.

[20] A. B. Solomon, M. Sharifpur, J. P. Meyer, J. Ibrahim, and B. Immanuel, "Convection heat transfer with water based mango bark nanofluids," 2017.

[21] B. Kristiawan, B. Santoso, W. E. Juwana, R. M. Ramadhan, and I. Riandana, "Numerical investigation of laminar convective heat transfer for TiO2/water nanofluids using two-phase mixture model (Eulerian approach)," in AIP Conference Proceedings, 2017, p. 030002.

[22] M. Manninen, V. Taivassalo, and S. Kallio, "On the mixture model for multiphase flow," Technical research centre of Finland, vol. 288, pp. 9-18, 1996.

[23] A. Naumann and L. Schiller, "A drag coefficient correlation," Z. Ver. Deutsch. Ing, vol. 77, 1935.

[24] M. Corcione, "Empirical correlating equations for predicting the effective thermal conductivity and dynamic viscosity of nanofluids," Energy Conversion and Management, vol. 52, pp. 789793, 2011.

[25] S. El Bécaye Maïga, C. Tam Nguyen, N. Galanis, G. Roy, T. Maré, and M. Coqueux, "Heat transfer enhancement in turbulent tube flow using $\mathrm{Al}_{2} \mathrm{O}_{3}$ nanoparticle suspension," International Journal of Numerical Methods for Heat \& Fluid Flow, vol. 16, pp. 275-292, 2006.

[26] S. E. B. Maïga, C. T. Nguyen, N. Galanis, and G. Roy, "Heat transfer behaviours of nanofluids in a uniformly heated tube," Superlattices and Microstructures, vol. 35, pp. 543-557, 2004.

[27] S. W. Churchill and H. Ozoe, "Correlations for laminar forced convection with uniform heating in flow over a plate and in developing and fully developed flow in a tube," journal of Heat Transfer, vol. 95, pp. 78-84, 1973. 